\title{
Genetic diversity and silencing suppression effects of Rice yellow mottle virus and the PI protein Christelle Siré ${ }^{1}$, Martine Bangratz-Reyser ${ }^{1}$, Denis Fargette ${ }^{2}$ and Christophe Brugidou*1
} \author{
le Développement (IRD), UMR RPB, 34394 Montpellier Cedex 5, France \\ Email: Christelle Siré - sire.christelle@gmail.com; Martine Bangratz-Reyser - martine.bangratz@mpl.ird.fr; \\ Denis Fargette - denis.fargette@mpl.ird.fr; Christophe Brugidou* - christophe.brugidou@mpl.ird.fr \\ * Corresponding author
}

Address: ${ }^{1}$ Institut de Recherche pour le Développement (IRD), UMR LGDP, 34394 Montpellier Cedex 5, France and 2Institut de Recherche pour

Published: 30 April 2008

Virology Journal 2008, 5:55 doi:10.1186/1743-422X-5-55

This article is available from: http://www.virologyj.com/content/5/I/55

(c) 2008 Siré et al; licensee BioMed Central Ltd.

This is an Open Access article distributed under the terms of the Creative Commons Attribution License (http://creativecommons.org/licenses/by/2.0), which permits unrestricted use, distribution, and reproduction in any medium, provided the original work is properly cited.
Received: 10 December 2007

Accepted: 30 April 2008

\begin{abstract}
Background: PTGS (post-transcriptional gene silencing) is used to counter pathogenic invasions, particularly viruses. In return, many plant viruses produce proteins which suppress silencing directed against their RNA. The diversity of silencing suppression at the species level in natural hosts is unknown.

Results: We investigated the functional diversity of silencing suppression among isolates of the African RYMV (Rice yellow mottle virus) in rice. The RYMV-PI protein is responsible for cell-to-cell movement and is a silencing suppressor. Transgenic gus-silencing rice lines were used to investigate intra-specific and serogroup silencing suppression diversity at two different levels: that of the virion and the PI silencing suppressor protein. Our data provide evidence that silencing suppression is a universal phenomenon for RYMV species. However, we found considerable diversity in their ability to suppress silencing which was not linked to RYMV phylogeny, or pathogenicity. At the level of the silencing suppressor PI alone, we found similar results to those previously found at the virion level. In addition, we showed that cell-to-cell movement of PI was crucial for the efficiency of silencing suppression. Mutagenesis of PI demonstrated a strong link between some amino acids and silencing suppression features with, one on the hand, the conserved amino acids C95 and C64 involved in cell-to-cell movement and the strength of suppression, respectively, and on the other hand, the non conserved F88 was involved in the strength of silencing suppression.
\end{abstract}

Conclusion: We demonstrated that intra-species diversity of silencing suppression is highly variable and by mutagenesis of $\mathrm{PI}$ we established the first link between silencing suppression and genetic diversity. These results are potentially important for understanding virus-host interactions.

\section{Background}

PTGS (post-transcriptional gene silencing) is conserved among eukaryote kingdoms and is a gene-regulatory mechanism involved in several control processes, includ- ing development, maintenance of genome stability, and defence against invasive pathogens. This molecular mechanism is initiated by double-stranded RNA (dsRNA) molecules, or RNA with secondary structures, and results in a 
reduced steady-state level of cognate cytoplasmic mRNA $[1,2]$, in which small RNAs (21-24 nucleotides) play crucial roles. Among these small RNAs, two functionally different RNAs, microRNAs (miRNA) and small-interfering RNAs (siRNA), have been characterized [3]. RNA-dependent RNA polymerase activity (RdRP) leads to production of dsRNAs molecules that are recognized and cleaved through the sclicer activity of RNAseIII (DICER-like protein). Thus small RNAs are loaded to RNA Induced silencing complex (RISC) and served as guides to cleave cognate mRNAs. It has been well described that PTGS is a major defence response against viruses [4]. Hence, viruses have been described as activators, as well as, targets of this mechanism [5-7]. To facilitate their replication and movement among host cells, plant viruses have acquired mechanisms to suppress gene silencing targeted at their RNA $[8,9]$. Such proteins are usually involved in viral pathogenicity [9] and also in virus spread, in cell-to-cell as well as in long-distance movement [10]. Many proteins that prevent, or suppress, the silencing of viral RNA have now been identified. These counter-defensive proteins can act at different steps in the PTGS pathway, e.g., involving the silencing signal itself or its subsequent propagation $[8,11]$. There is considerable diversity in the sequences of these suppressor proteins, as well as in their targets and modes of action [12-14]. This suggests that viruses have no general strategy for suppressing the silencing of their RNA.

The Rice yellow mottle virus, belonging to the Sobemovirus genus, is endemic to Africa and is the major pathogen of irrigated rice $[15,16]$. Its genome and particle structure have been described $[17,18]$. P1 is a $18-19 \mathrm{kDa}$ protein encoded by the first open reading frame (ORF) of RYMV positive sense single-stranded RNA, which contains four partially overlapping ORFs [19]. With up to $17.8 \%$ amino acid sequence divergence, the genetic diversity of P1 protein is higher than for other viral proteins [19]. This protein is required for viral replication and cell-to-cell movement [20]. It also acts as a non-autonomous-cell silencing suppressor in Nicotiana benthamiana $[9,21]$.

It is well known that viral suppressors differ considerably in their structure and function [22]. However, at the virus species level, functional diversity of these proteins is unknown. In addition, nothing is known at the viral level as to how they suppress the silencing of their RNA during the infection of a natural host. We investigated both of these aspects using RYMV and P1 protein as model systems, to study the functional diversity of silencing suppression from various virus isolates. In this paper, we analysed silencing suppression of RYMV in its natural host at the virion and P1 protein levels. Such an analysis was possible since genetic diversity of the RYMV is well characterised $[19,23,24]$ and its phylogeography could be reconstructed in detail to highlight links between the geographical and ecological origins of virus isolates $[19,25]$. Using a transgenic rice line, containing a silenced $\beta$-glucoronidase (GUS) transgene (iudA), we investigated by GUS activity reversion the functional diversity of PTGS suppression upon virion inoculation or ectopic P1 gene expression. We thus were able to demonstrate for the first time the high diversity of silencing suppression at the intra-species level, suggesting a complex mechanism in silencing suppression at the virus scale. Using P1 mutants we found that cell-to-cell movement and the efficiency of silencing might be linked with variation in the efficiency of silencing suppression.

\section{Methods \\ Plant material}

Transgenic $O$. sativa L. (O. s.) spp. japonica cv. Nipponbare containing the uidA (gusA) transgene from pCAMBIA 1301 (GenBank accession No. AF234297) and carrying a single copy of T-DNA [26] (C. Sallaud, unpublished data) were used. Transgenic line L4 constitutively expresses the uidA gene and the transgenic line L10 is gussilenced (Figure 1). L10 expressed a PTGS phenotype for expression of the uidA gene on the basis of GUS staining in leaves or roots. With gus-specific siRNA detection, we correlated the L10-phenotype to PTGS and demonstrated its stability over the lifetime of vegetative plants from germination (Figure 1). L10 was used as a model in our silencing suppression studies during host-pathogen interactions. Plants were grown and maintained in controlled conditions in a confined greenhouse (CGG consent for GMO culture $\mathrm{n}^{\circ} 3576$ ) under $12 \mathrm{~h}$ light at $28^{\circ} \mathrm{C}, 12 \mathrm{~h}$ dark at $24^{\circ} \mathrm{C}$ and at a relative humidity of $70 \%$. As a con-

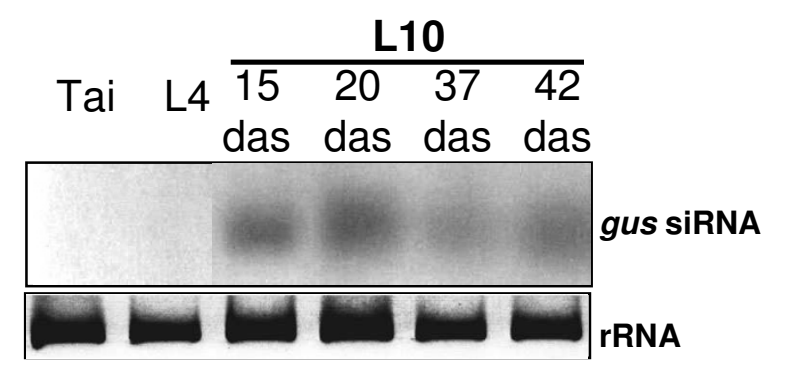

\section{Figure I}

Assessment of the PTGS mechanism with gus-specific siRNA detection by Northern blot in different rice varieties at different stages of plant development. The rice plants used were Tai; non transgenic cv. Taipei, L4; a transgenic gus-expressing line, LI O; a gus-silenced transgenic line revealed by histochemical staining collected at I5, 20, 37 and 42 days after seeding (das). EtBr staining of rRNA served as a loading control. 
trol, wild-type O. sativa spp. japonica cv. Taipei (Tai.) was used.

\section{Virus isolates and inoculation}

We used 10 fully sequenced RYMV isolates belonging to different serogroups and representative of viral diversity in Africa (i.e. with $9.9 \%$ maximum diversity) $[19,23]$, these were; BF1, CI63, CI4, Ni1, Ni2, Mg1, Tz3, Tz5, Tz8 and Tz11. There was a second set of 10 isolates belonging to serogroup 2, showing variable pathogenicity assessed through symptom intensity, but low sequence diversity (2\%). These were; CI110, 111, 112, 113, 114, 115, 116, 121, 129, and 138 [27] (Figure 2). They were independently propagated in the susceptible cultivar $O$. sativa spp. indica $\mathrm{cv}$. IR64.

Two weeks after seeding, plants ( 2 leaves) were mechanically inoculated as described elsewhere [28] with diluted sap $(1 / 10 \mathrm{w} / \mathrm{v})$. Each isolate was independently inoculated into 20 plants that were grown separately to limit cross contamination. Viral inoculum were adjusted to a standard concentration, as estimated by DAS-ELISA assays, to prevent variation in silencing suppression due to differences in initial virus delivery. In order to avoid bias due to inoculation heterogeneity, leaf samples were collected from each inoculated plant at 35 or $40 \mathrm{dpi}$ and separated into two independent samples before being ground for proteins (fluorimetry, ELISA and western) and RNA extractions.

\section{Plasmid construction and biolistic delivery experiment}

P1 sequences with UTR (from 1 to 709 nt) [17] from five isolates representative of the diversity of $\mathrm{P} 1$ with a divergence up to $17.8 \%$ were selected. These isolates are representative of the diversity of the other parts of the genome as phylogenetic reconstruction from the $\mathrm{P} 1$, the $\mathrm{CP}$ and the full genome are congruent. They were cloned into the CaMV 35S constitutive promoter and terminator, that were named sTz3; sMg1; sCI63; sBF1; sTz8. PCR fragments of P1 sequences (underlined) were amplified with: forward GAATTCAAGCTTGACAATTGAAGCTAGGAAAGGAGC, reverse GAATTCTCTAGACGCGGCC GCTATCAA, and cloned into the XbaI/HindIII (in bold) restriction site from the $35 \mathrm{~S}$ cassette. These constructs were delivered twice onto pieces of L10 leaves (collected 2 weeks after seedling) by particle bombardment. For each P1 tested, 20 leaves were cut into $10 \mathrm{~cm}$ strips. In order to detect the specific effect of $\mathrm{P} 1$ and to avoid potentially unfavourable viral translation, we analysed leaves at 2 days post-delivery (dpd). Histological experiments were performed in the presence of ferro- and ferri-cyanide, so as to ensure wide range spread of coloration was not influenced by stain spreading and only reflected presence of GUS activity.

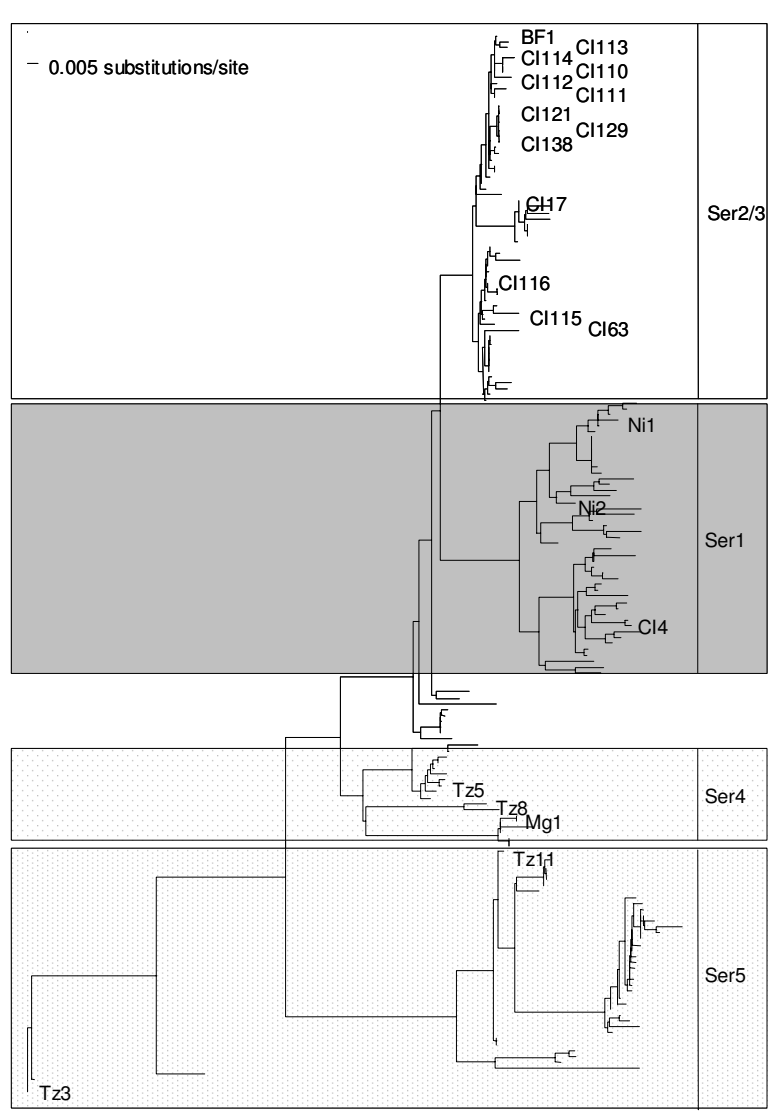

Figure 2

ORF4 (CP)-based phylogenetic tree. Phylogenetic tree reconstructed from 179 partially sequenced isolates from the 15 countries where RYMV has been reported: Benin, Burkina Faso (BF), Chad, Ivory Coast (Cl), Cameroon, Ghana, Guinea, Kenya, Madagascar (Mg), Mali, Niger, Nigeria (Ni), Sierra Leone, Tanzania (Tz) and Togo. The Kimura2 substitution model with estimates of the alpha parameter of the gamma shape was applied. The serotype of the isolates defined by reactions with a set of monoclonal antibodies in ELISA tests (47) is indicated (by vertical bars) at the right of the figure.

\section{Biolistic delivery}

Five micrograms of sP1s were inoculated onto pieces of leaves from the L10 gus-silenced line by biolistic delivery (Biorad Biolistic PDS 1000/He) after $3 \mathrm{~h}$ incubation in MES buffer containing 10\% (w/v) sucrose. Leaves were bombarded at a pressure of $1100 \mathrm{psi}$ and a flight distance of $6 \mathrm{~cm}$ with tungsten-coated particles. Each construct was delivered to 20 leaf pieces that were bulked for analysis at the end of the experiment. Leaves were then placed at $26^{\circ} \mathrm{C}$ for 2 days in $16 \mathrm{~h}$ light, $8 \mathrm{~h}$ dark at a relative humidity of $60 \%$, on $1.5 \%$ phytagel and $0.5 \mathrm{w} / \mathrm{v}$ MES containing $3 \%(\mathrm{w} / \mathrm{v})$ sucrose. 


\section{RNA and protein analyses}

Total RNA was extracted from rice leaves with TRIzol reagent (Invitrogen ${ }^{\mathrm{TM}}$ ) according to the manufacturers' instructions. Analysis of low molecular weight RNA was performed on $15 \mu \mathrm{g}$ total RNA as described previously [29]. Analysis of mRNA was performed with NorthernMax $^{\circledR}$-Gly $\left(\right.$ Ambion $^{\circledR}$ ) as recommended by the manufacturer. Radio-labelling of the probe and hybridization was performed as done in ref. [30]. A 808 bp PCR amplified fragment ( 808 to $1616 \mathrm{bp}$ ) of GusA was used for the specific probe preparation. Radio-labelled signals were detected either by autoradiography or by scanning with Typhoon (Amersham). RNA band intensities were quantified using Image Quant software (Molecular Dynamics).

Soluble proteins were extracted from rice leaves in a sodium phosphate buffer $\left(50 \mathrm{mM} \mathrm{NaHPO}_{4}, 10 \mathrm{mM}\right.$ $\mathrm{Na}_{2}$ EDTA, $1 \mathrm{mg} \cdot \mathrm{ml}^{-1} \mathrm{~N}$-Laurylsarcosine, $0.1 \% \mathrm{v} / \mathrm{v}$ Triton $\times 100$ ) by two successive centrifugations of $20000 \mathrm{~g}$ at $4{ }^{\circ} \mathrm{C}$. The Bradford colorimetric method (Coomassie protein assay kit, Pierce) [31] was used for protein quantification. Twenty micrograms of protein were resolved by SDSPAGE and transferred by electroblotting onto a nitrocellulose membrane (Trans-Blot ${ }^{\oplus}$ Transfer Medium, Biorad). A diluted rabbit polyclonal antibody directed against the P1 protein (1/500) was used and revealed by a second (1/ 40000), horseradish peroxidase-conjugate (Pierce) through Supersignal ${ }^{\circledR}$ West-Pico chemiluminescence substrate. Blots were exposed to CL-XPosure ${ }^{\mathrm{TM}}$ film (Pierce).

\section{DAS ELISA assays}

The virus concentration was evaluated by DAS-ELISA as described previously [32]. DAS-ELISA was performed with diluted $(1 / 1000 \mathrm{v} / \mathrm{v})$ polyclonal antiserum against an isolate from Madagascar (RYMV-Mg). Positive reactions were detected after incubation with alkaline phophatase-conjugated polyclonal antibody to RYMV and substrate, with absorbance read using a Multiskan fluorimeter (Labsystem).

\section{GUS assays}

Histochemical staining for GUS activity and GUS assays were performed according to Jefferson [33] and involved pieces of leaves randomly collected from two to five plants at 1 and 2 dpi (inoculated leaves), and 7, 14, 35 and 40 dpi (systemically infected leaves).

As described previously [34], proteins were incubated with $1 \mathrm{mM}$ of 4-methylumbelliferyl- $\beta$-D-glucuronide (MUG, Sigma $^{\circledR}$ ). Fluorescence was measured at $15 \mathrm{~min}$ intervals for $2 \mathrm{~h}$ with a Fluoroskan fluorimeter (Labsystem), with a $365 \mathrm{~nm}$ excitation filter and a $455 \mathrm{~nm}$ emission filter. Calibration was performed with quantification of fluorescence of soluble 4-methylumbelliferone (MU, Sigma $^{\circledR}$.

\section{Results}

Silencing suppression diversity at the RYMV species level We investigated the diversity of RYMV efficiency in silencing suppression and used a transgenic gus-silenced rice line (L10). As seen in Figure 1, silencing of the gus transgene, leads to an absence of GUS activity, and is accompanied with a strong accumulation of gus specific siRNA. This accumulation is maintained during the life-cycle of rice plants (Figure 1). Moreover, infection with the RYMV virus leads to a restoration of GUS activity concomitant with a decrease of gus-siRNA accumulation. Assuming that silencing suppression activity of RYMV involves restoration of the GUS phenotype and a decrease of steadystate levels of gus-siRNA, we quantified silencing suppression efficiency by evaluating the decrease in steady state levels of siRNA. We separately inoculated $10 \mathrm{RYMV}$ isolates that differed in their coat protein (CP) (Figure 2). From 1 dpi, we revealed GUS reversion for all isolates by observing the blue histochemical staining patterns in both L10-infected leaves and positive controls (i.e. transgenic L4 lines that constitutively expresses the uidA transgene) whereas in non-inoculated (NI) and mock-inoculated (BI) L10 leaves, GUS activity was undetectable (Figure 3A) indicating that the reversion of GUS activity in L10-inoculated plants was only due to RYMV and not to mechanical stress caused by the inoculation.

Because histochemical staining of GUS is not a quantitative method the reversion of uidA gene expression in L10 was assayed by fluorimetric quantification of GUS activity, in systemically infected leaves. We found that RYMV isolates differed in their efficiency to reverse the constitutive silencing, as illustrated by the heterogeneity of restored GUS activity (Figure $3 \mathrm{~B}$ ). In each serogroup (Figure $3 \mathrm{~B}$ ), we detected a contrasting pattern of reactivation for the uidA transgene. In S1, the isolates CI4, Ni1 and $\mathrm{Ni} 2$ exhibited distinct effects on silencing suppression (Figure 3B, lanes 3-5). Similarly, the S4 Mg1 isolate weakly suppressed silencing, whereas a strong effect was obtained for the Tz8 isolate (Figure 3B, lanes 8, 10). Finally, strong suppression leading to higher GUS activity was detected for the Tz3 and Tz11 isolates belonging to the S5 serogroup (Figure 3B, lanes 11-12). This result showed that the ability to suppress PTGS was not correlated with the viral phylogeny.

Moreover, we found that viral content was not correlated with GUS activity, as illustrated by isolates belonging to the same serotype $\mathrm{Ni} 2$ and $\mathrm{CI} 4$, or, CI63 and BF1 isolates (Figure 3C, lanes 3 and 4 or 4 and 5). We also noted that the diversity of silencing suppression displayed by these RYMV isolates was not correlated with viral pathogenicity (data not shown). Indeed, the most pathogenic isolate, $\mathrm{BF} 1$, was not the strongest in suppressing PTGS. 
L10

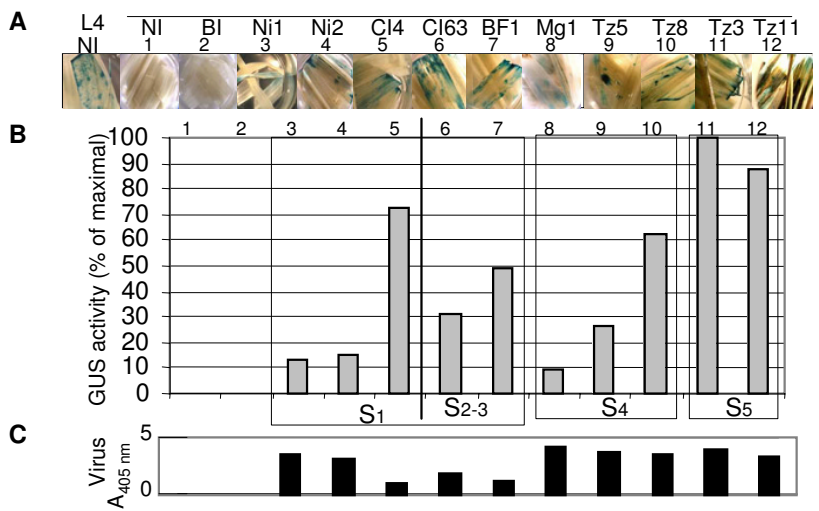

Figure 3

Heterogeneous silencing suppression caused by highly diverse isolates. (A) GUS histochemical staining analysis of gus-silenced transgenic LIO leaves harvested at 35 dpi, controls correspond to non-inoculated (NI) and bufferinoculated $(\mathrm{BI})$ leaves from transgenic gus-expressing $\mathrm{L} 4$ and gus-silenced $\mathrm{LIO}$. In boxes, isolates belonging to the same serogroup (S, Figure 2) are compared. (B) GUS activity is measured by fluorimetry and is expressed as a percentage of maximal activity measured in Tz3 inoculated samples. (C) ELISA-based measurement of virus content and western blot analysis of $\mathrm{PI}$ protein.

Taken together, these results highlighted the prevalence of silencing suppression within the species and showed that gus-silenced gene reversion was dependent on viral isolate.

\section{Silencing suppression diversity at the RYMV serogroup level}

As plants infected with different RYMV isolates exhibited variable GUS activity, we investigated the diversity of this restoration at the serogroup level. Thus we considered isolates from the Ivory Coast belonging to the least variable RYMV serogroup S2 (diversity around 2\% based on CP sequence) (Figure 2). Ten representative isolates of S2 were chosen for homogeneous biological characters (same collection date and geographical localisation) and were inoculated into L10 plants.

Silencing suppression showed by the restoration of GUS activity was followed by histochemical staining of GUS at $1,2,7,15,17,21,27,31$, and $40 \mathrm{dpi}$. At $40 \mathrm{dpi}$, steadystate siRNA levels were monitored with Northern blots. Gus-specific siRNA were not detected in systemically infected leaves in contrast to NI or BI L10 leaves (Figure 4A). This revealed that uidA gene silencing had been reverted by all S2 isolates tested. To analyze more closely the qualitative effect of the different isolates, we compared

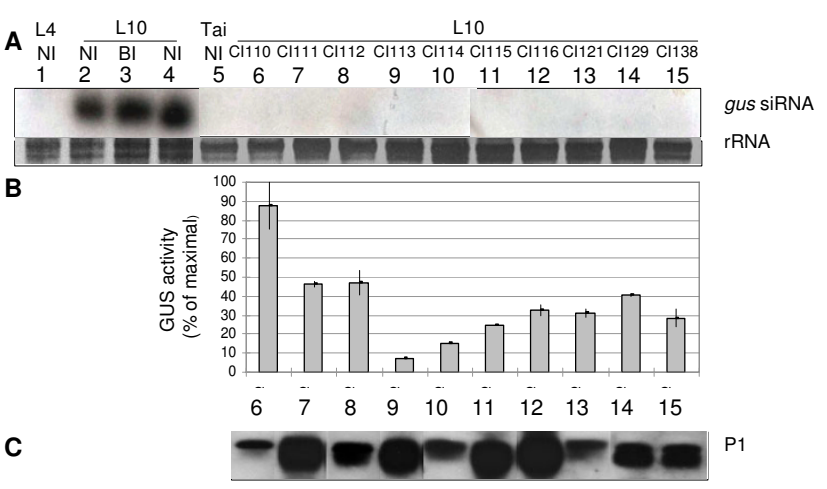

Figure 4

Heterogeneous silencing suppression caused by isolates from a homogeneous phylogenetic group (i.e. S2 isolates), at 40 dpi. (A) Northern blot analysis of gussiRNA. Controls group together: positive controls for gussiRNA detection corresponding to RNA from LIO either $\mathrm{NI}$ (non-inoculated) or BI (buffer-inoculated) and RNA from non transgenic Tai, or transgenic L4 plants as negative controls. $\mathrm{EtBr}$ staining of rRNA served as a loading control. (B) GUS activity is measured by fluorimetry and is expressed as a percentage of the maximal activity measured in $\mathrm{CII} \mathrm{O} 0$ inoculated plants. Analyses were carried out with soluble protein extracted from LIO leaves infected by different isolates. Data represent average values of two independent measurements with standard deviations indicated. (C) Western blot analysis of PI protein.

GUS activity levels measured by fluorimetry (Figure 4B) to viral amounts measured by ELISA (Table 1) in systematically infected leaves. An analysis of covariance revealed that at $40 \mathrm{dpi}$ a large part of the variability in silencing suppression was due to an isolate effect, although part of the reversion was due to an effect of virus content (Table 1 ). We thus revealed highly heterogeneous responses in GUS activity reversion following viral infection (Figure $4 \mathrm{~B}$ ). Isolate CI110, is considered to be strong suppressor of constitutive silencing in the iudA gene, (Figure 4B). The weaker suppressors were isolates CI113 and 114, with less than 20\% maximal activity restoration (Figure 4B). Western blot analyses showed that the efficiency of silencing suppression was not correlated with RYMV-P1 protein suppressor accumulation in leaves (Figure 4C). As all isolates belong to the same serogroup, this quantitative variation of P1 accumulation should not be linked to polyclonal antibody affinity. In addition, sequences analysis of P1 proteins found no obvious correlation between the efficiency of silencing suppression and genetic diversity of the P1 protein (data not shown) suggesting that silencing suppression when analyzed at the virion scale is more complex than previously thought. As noted above, the efficiency of silencing suppression is not correlated to symptoms expressed by these isolates (data not shown). 
Table I: Virus content and restoration of GUS activity

\begin{tabular}{|c|c|c|}
\hline & Gus activity & $\mathrm{A}_{405 \mathrm{~nm}}$ \\
\hline CIIIO-I & 80 & 0,53 \\
\hline CIIIO-2 & 60,4 & 0,14 \\
\hline CIIII-I & 38,5 & 0,62 \\
\hline CIIII-2 & 35,7 & 0,49 \\
\hline ClII2-I & 32,2 & 0,22 \\
\hline $\mathrm{ClI} / 2-2$ & 42,8 & 0,26 \\
\hline CIII3-I & 5,8 & 0,48 \\
\hline $\mathrm{ClI} / 3-2$ & 5,6 & 0,49 \\
\hline CIII4-I & 12,3 & 0,39 \\
\hline CIII4-2 & 12,6 & 0,27 \\
\hline CIII5-I & 20 & 0,54 \\
\hline CIII6-I & 23,9 & 0,84 \\
\hline CIII6-2 & 28,4 & 0,66 \\
\hline CIIII-I & 23,5 & 0,27 \\
\hline CII2I-2 & 26,6 & 0,55 \\
\hline CII29-I & 33,1 & 0,58 \\
\hline ClI29-2 & 31,8 & 0,29 \\
\hline CII38-I & 26,6 & 0,31 \\
\hline \multirow[t]{2}{*}{ CII 38-2 } & 19 & 0,23 \\
\hline & F. ratio & $\mathbf{p}$ \\
\hline Virus content effect & 8.97 & 0.02 \\
\hline Isolate effect & 33.89 & 0.00002 \\
\hline
\end{tabular}

Effect of virus content expressed in absorbance units read at $405 \mathrm{~nm}$, on restoration of GUS activity measured by fluorimetry and expressed in pmol MU/min/ $\mu \mathrm{g}$ protein. Results of covariance analyses to evaluate both virus content and isolate effects with the Fisher test.

Taken together our results at the virion scale demonstrate that the accumulation and genetic diversity of the P1 suppressor protein were not correlated to heterogeneity in the reversion of GUS activity that we observed.

\section{Effect of ectopic PI protein expression on silencing suppression}

As the effect of RYMV on uidA silencing suppression was not linked to viral diversity, pathogenicity or P1 accumulation, we attempted to assess the particular effect of the P1 protein identified as the RYMV silencing suppressor protein [9]. Different P1s representative of the viral diversity were cloned under control of the CaMV $35 \mathrm{~S}$ promoter. This was done in order to determine whether the sequence diversity of this suppressor reflects functional diversity and to accurately determine the qualitative effect of the P1 protein on silencing suppression.

We demonstrated a lack of effect due to biolistic delivery and the expression vector by using empty 35S (Figure 5A and 5B lane 5). At 1 day post delivery (dpd), we revealed the reversion of GUS activity, except for sTz8 for which GUS activity was only observed at 2 dpd (Figure 5A). We

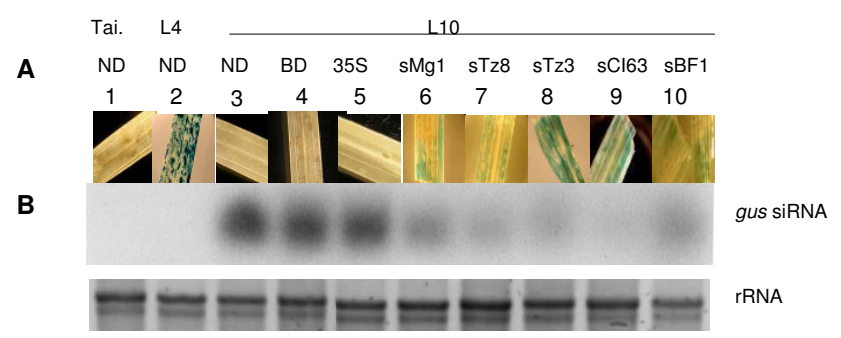

Figure 5

Effect of the PI protein from different RYMV isolates on silencing suppression in rice. Transgenic LIO leaves were analysed after different treatments; non-biolistic delivery (ND), buffer delivery (BD), biolistic delivery with a empty $35 \mathrm{~S}$ vector (35S), or vectors containing different $\mathrm{SPI}$ from RYMV isolates representative of the viral phylogeny $(\mathrm{Cl63}$, $\mathrm{MgI}, \mathrm{Tz8}, \mathrm{Tz3}, \mathrm{BFI})$. Non transgenic Tai and transgenic L4 served as controls. (A) Photographs correspond to GUS staining at $2 \mathrm{dpd}$ of inoculated leaves. (B) Quantitative effect of different PI at 2 dpd on gus-specific siRNA with Northern blot experiments. EtBr staining of rRNA served as a loading control.

thus demonstrated for the first time in a natural host, that all P1s from different RYMV isolates were silencing suppressors. In addition, we observed the reversion of GUS activity over the entire leaf, even where the P1 protein had not been delivered, suggesting strong movement of this protein (Figure 5A).

To further examine whether P1 acts differently in relation to variation in its sequence, we evaluated the steady-state level of gus-specific siRNA by Northern blot. Every P1 induced a decrease in the steady-state level of gus-siRNA, as compared to siRNA detected in L10 controls (ND, BD and 35S) (Figure 5B). Moreover, as shown in Figure 5B, the different $\mathrm{P} 1 \mathrm{~s}$ exhibited contrasting activity in silencing suppression, as revealed by the different siRNA patterns. These results highlight the qualitative effect of different P1s and that they could be grouped into two classes according to their efficiency of suppression. Indeed, we observed that GUS activity restoration with sCI63, sTz3 and Tz8 was accompanied by a dramatic decrease in siRNA levels. Consequently, we concluded these proteins are highly efficient in transgene-induced silencing suppression in rice. Conversely, in case of sBF1 and sMg1, we observed a slight decrease in siRNA levels (Figure 5B), and they were thus classified as weak silencing suppressors.

Furthermore, as previously demonstrated at the virion scale, the efficiency of these silencing suppressors is not correlated with viral phylogeny. Indeed, according to RYMV evolutionary history [19], P1s from isolates belonging to the same phylogenetic group can be either strong (sCI63) or weak silencing suppressors (sBF1) (Figure 2 
and 5B). In addition, P1s from distant isolates were similar in their silencing suppression efficiencies, as illustrated by the weak suppressors sBF1 and sMg1 (Figure 2 and 5B).

\section{Movement of $P I$ protein and silencing suppression}

As we found a qualitative effect of the different P1s, and as it has been demonstrated that silencing suppression and cell-to cell movement of Potato potexvirus X (PVX) are linked [35], we investigated the involvement of cell-to-cell movement of P1 on the qualitative variation in silencing suppression (Figure 6A). We carried out an experiment to analyze P1 protein accumulation at the site of delivery (del) and in distal (dis) areas of L10-inoculated leaves. To do so, we co-bombarded 20 pieces of L10 leaves with every sP1 construct described above and associated with a 35S-GFP plasmid. Under UV illumination at $2 \mathrm{dpd}$, we were able to discriminate the delivery area from the distal area by GFP fluorescence. We could detect green areas corresponding to the delivery zone (del) and red areas due to chlorophyll fluorescence corresponding to the distal zone (dis) (Figure 6A). To limit any contamination by P1 outside from the delivery zone, we enlarge the delivery zone by an additional $1.5 \mathrm{~cm}$ which leads, in addition to a $6 \mathrm{~cm}$ flight distance, to an incompatible zone to receive any particles.

We compared the steady-state level of gus-siRNA and mRNA, in the delivery and distal areas for each sP1 protein previously selected for a range of variation in their efficiency of silencing suppression (Figure 6B). For the sTz3 protein, accumulation of gus-siRNA and mRNA were similar in del and dis areas (lanes $4-5$ ). For the sCI63 protein, we observed a weak accumulation in the both areas for gus-siRNA, and strong accumulation mainly in del area for gus-mRNA (lanes 8-9). For the sMg1 protein, we observed a contrasting situation between the del and dis areas; lower accumulation of gus-si-RNA and accumulation of mRNA in the del area, and an absence of gusmRNA in the dis area (Figure 6B, lanes 6-7). Then, for the same samples, we investigated the presence of $\mathrm{P} 1$ in the del and dis areas by western blot. Similar P1 protein accumulation was revealed in del and dis zones for sTz3 and sMg1 (Figure 6C, lanes 4-7), and only in the dis zone for sCI63 (Figure 6C, lanes 8-9). Although we cannot rule out the bombardment of P1 outside of GFP area, the strong accumulation of $\mathrm{P} 1$ detected in distal areas seems to favour the idea that of there being cell-to-cell movement from delivery to distal area of $\mathrm{P} 1$ proteins in rice leaves. This would help clarify our previous observation of GUS activity being detected across entire leaves (see Figure $5 \mathrm{~A}$, lanes 2 and 6 compared to 8 or 9). Furthermore, we observed differences in P1 accumulation as shown for sCI63 (only detected in the dis area, Figure 6C lanes 8-9), where a weak accumulation of gus-siRNA was correlated with gus-mRNA expression, as compared to levels observed for sTz3 and sMg1. It therefore seems likely for sCI63 that the faster movement of this $\mathrm{P} 1$ protein is associated with its high efficiency in silencing suppression.

In contrast, for sMg1 we observed a different situation with the accumulation of P1 in the dis area which was not correlated with a decrease in gus-siRNA and the expression of gus-mRNA (Fig 6B and 6C, lanes 6-7). For sMg1, although movement of P1 occurred its lack of effects on gus-siRNA was likely caused by its weaker efficiency in silencing suppression.

\section{Functional amino acids in $\mathbf{P I}$ proteins}

As we demonstrated major differences in the silencing suppression efficiencies of different P1 proteins (Tz8, BF1, CI63, Mg1 and Tz3), we attempted to assign amino acid diversity to functional effects with ClustalW alignments [36] (Figure 7A).

First, we identified the putative eukaryotic Zn-finger motif $\left(\mathrm{C} 64(\mathrm{x})_{2} \mathrm{C} 67(\mathrm{x})_{24} \mathrm{C} 92(\mathrm{x})_{2} \mathrm{C} 95\right)$ which is conserved across the RYMV phylogeny (Figure 7A). This kind of motif has been reported to be crucial for silencing suppression activity [37]. We introduced two independent single mutations in the Tz3 Zn-finger with PCR amplification in cysteine 64 and 95 (Cystein changed by Serine, C64S et C95S). Secondly, when comparing sequences of the strongest silencing suppressor (sTz3) and the weaker silencing suppressor (sMg1) we detected two amino acids specific to sTz3 (i.e. N19 and F88) (Figure 7A). We used PCR amplification to introduce two independent single mutations in the sTz3 sequence at asparagine 19 (Asparagine changed by Isoleucine, N19I) and phenylalanine 88 (Phenylalanine changed by Tyrosine, F88Y). The efficacy of these mutants to abolish silencing of the uidA transgene in L10 was tested following biolistic delivery. The effects of these mutations were compared with wild-type sTz3 and sMg1 silencing suppressor proteins.

At the histochemical and molecular levels (i.e. gus-specific si- and mRNA detection), we demonstrated that none of the four mutations completely abolished the suppression effect of sTz3. Nevertheless, the single amino acid mutation C95S impaired the ability of P1 to suppress uidA silencing in the distal part of leaves (high level of gussiRNA), suggesting that this mutation affects the cell-tocell movement of P1 (Figure 7B, lanes 12-13). Conversely, mutations F88Y or C64S both decreased silencing efficiency, as shown by the steady-state level of gus-siRNA in the del and dis zones being higher than observed with sTz3 (Figure 7B, lanes 4-7). Finally, mutation N19I did not affect the silencing suppression efficiency of the P1 protein relative to $s T z 3$, as shown by similar pattern of gus-siRNA and gus-mRNA (Figure 7B, lanes 8-9). Together these results demonstrate that mutations highly influence 


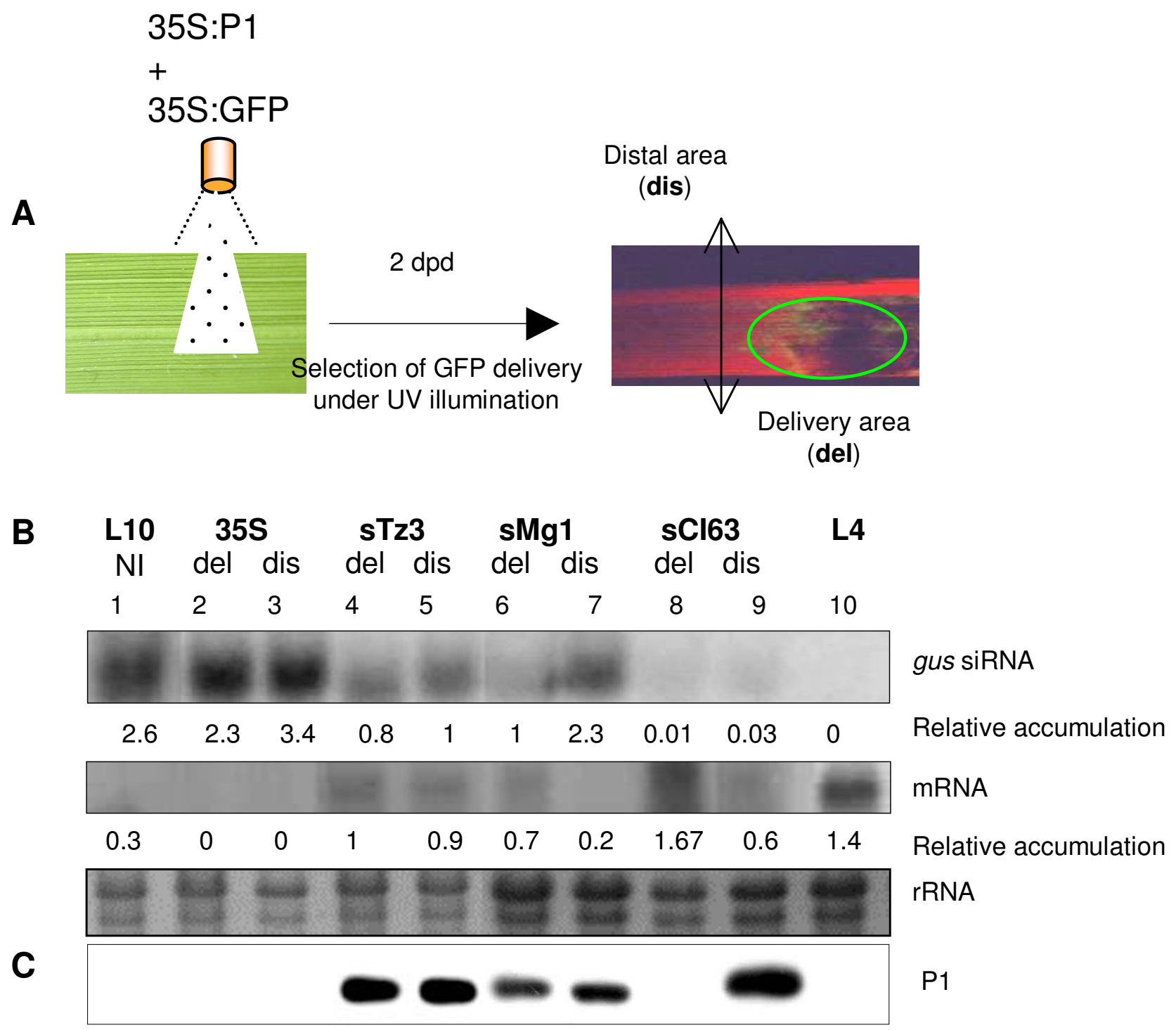

Figure 6

Movement of PI protein and silencing suppression. (A) Schematic representation of the experimental design to distinguish delivery (del) and distal (dis) points after bombardment. (B) Northern analysis of gus-siRNA and mRNA at 2 days post delivery (dpd) with sTz3, MgI and Cl63 PIs in the del or dis parts of the leaf. 35S is an empty cassette (negative control) and EtBr staining of rRNA served as a loading control. (C) Western blot analysis of PI protein. Relative accumulation to the loading control are shown, RNA band intensities were quantified using Image Quant software (Molecular Dynamics).

the quantitative (Figure $7 \mathrm{~B}$, lanes $12-13$ ) and qualitative (Figure 7B, lanes 6, 8, 10) expression of P1 activity. Finally, we found that the cystein 95 belonging to the putative zing finger is essential for the cell-to-cell movement of P1 and cystein 64 and phenylalanine 88 were involved in the efficiency of silencing suppression of the P1-Tz3 protein.

\section{Discussion}

Previous studies have shown the potential of viral proteins as silencing suppressors, but only outside of their natural context [38]. For RYMV, the P1 protein was identified as a silencing suppressor in N. benthamiana, which is not a natural host [9]. The novelty of our study was the focus on the characterisation of silencing suppression 


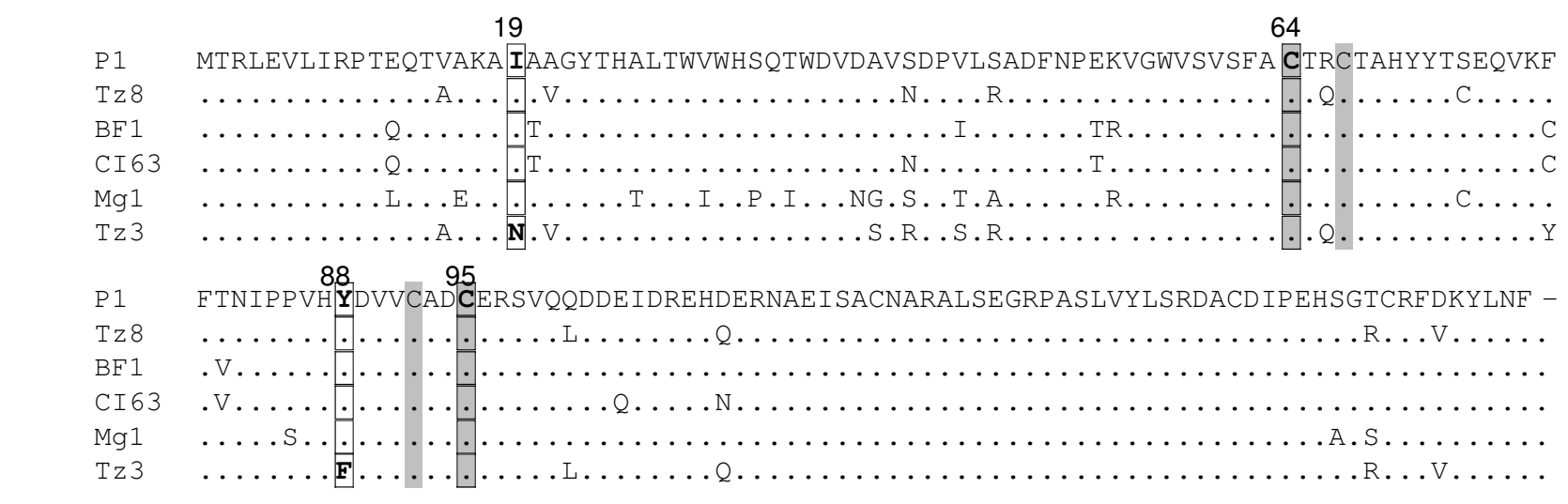

\begin{tabular}{|c|c|c|c|c|c|c|c|c|c|c|c|c|}
\hline \multirow[t]{2}{*}{ B } & \multicolumn{2}{|c|}{$35 S$} & \multicolumn{2}{|c|}{ sTz3 } & \multicolumn{2}{|c|}{ F88Y } & \multicolumn{2}{|c|}{ N19l } & \multicolumn{2}{|c|}{ C64S } & \multicolumn{2}{|c|}{ C95S } \\
\hline & de & dis & del & dis & del & dis & del & dis & del & dis & del & dis \\
\hline 1 & 2 & 3 & 4 & 5 & 6 & 7 & 8 & 9 & 10 & 11 & 12 & 13 \\
\hline 2.6 & 2.3 & 3.4 & 0.8 & 1 & 1.6 & 1.3 & 0.5 & 0.5 & 1.3 & 1 & 0.8 & 5.3 \\
\hline 0.3 & 0 & 0 & 1 & 0.9 & 0.4 & 0.37 & 0.7 & 0.9 & 0.7 & 0.7 & 0.8 & 0 \\
\hline side & & & & & & & & & & & & \\
\hline
\end{tabular}

gus siRNA

Relative accumulation mRNA

Relative accumulation

rRNA

\begin{abstract}
Figure 7
Functional amino acids of $P I$ involved in silencing suppression. (A) ClustalW alignment of $\mathrm{PI}$ proteins with the putative $\mathrm{Zn}$-finger (in grey) and detection of potential amino acids involved in silencing suppression that were point mutated (in box). (B) Northern analysis of gus-siRNA and mRNA at 2 days post delivery (dpd) with sTz3, and mutated sTz3 (F88Y, NI9I, $\mathrm{C64S}$ and C95S) in the del or dis parts of the leaf (see Figure 5A). 35S is an empty cassette (negative control) and EtBr staining of rRNA served as a loading control. Relative accumulation to the loading control are shown, RNA band intensities were quantified using Image Quant software (Molecular Dynamics).
\end{abstract}

with RYMV virions and the role of the P1 protein when infecting a natural host. We demonstrated the efficiency of the RYMV-virion as a constitutive-silencing suppressor in rice. We found for the first time that highly diverse RYMV isolates are all able to suppress a constitutive gus-silenced transgene, indicating that silencing suppression is a vital feature for RYMV. Through the quantitative analysis of GUS activity, we demonstrated that silencing suppression was dependent on viral presence in systemically infected leaves, but high silencing suppression is not strictly linked with a high viral content. Furthermore, we have also shown that the efficiency of GUS silencing reversion is isolate-dependent. Finally, we demonstrated that variation in silencing suppression was not linked to viral phylogeny and it occurred at the species and serogroup levels.
In order to explain the diversity observed at the virion scale, we focused on the P1 protein previously identified as a RYMV silencing suppressor [9]. Our results showed that the strength of silencing suppression at the virion scale was neither correlated with P1 protein accumulation, nor strictly correlated to P1 sequence variation. This complex picture at the virion scale suggests that the activity of the silencing suppressor protein is probably highly regulated during host-virus interactions. We cannot rule out the presence of additional silencing suppressor proteins encoded by RYMV, as has been shown for the Citrus tristeza virus [39], nor can we exclude the possibility of additional mechanisms known to overcome PTGS. For example, the Brome mosaic virus replicates its viral genome in endoplasmic reticulum where dsRNA is not accessible $[40,41]$, and PVX has developed high-speed replication to outrun the mobile silencing signal [41]. 
Our observations have shown that silencing suppression efficacy and isolate pathogenicity were not correlated. This could contradict the hypothesis that silencing suppressors determine pathogenicity [42]. Although the basic hypothesis is that viral pathogenicity can be determined by the influence of a viral suppressor on miRNA pathways $[43,44]$ it was recently demonstrated that not all silencing suppressors affect miRNA [45]. During infection in a natural context, suppressors are likely to be highly regulated so as to minimize their effect within the host. The silencing suppression effect of each RYMV isolate could thus be adapted to balance the viral effect (i.e. pathogenicity) in the host, while limiting viral-induced host gene silencing in order to preserve the integrity of the plant machinery during the infection process. RYMV also goes to different cytoplasmic organelles that could secondarily increase its pathogenicity [46]. This could mask the primary effect of the silencing suppressor. Interestingly, it is also known that some isolates can affect rice genotypes differently, suggesting that the silencing suppression state, as well as pathogenicity, could be genotype-dependent [27].

Our results, obtained with the $\mathrm{P} 1$ protein alone, showed a similar tendency in silencing suppression as to those obtained with virions suggesting a major role for the P1 silencing suppressor. As observed at the scale of the virion, we observed a distinct functional variation of $\mathrm{P} 1$ proteins based on the efficiency of silencing suppression, which was not correlated with the viral phylogeny.

We correlated variation in silencing suppression and sequence variation of protein P1 by molecular analyses, with independent point mutations in the $\mathrm{Zn}$-finger motif or to selected amino acids identified by comparing sequence data between Tz3 (strongest suppressor) and Mg1 (lowest suppressor) P1 proteins. P1 mutants only showed partial alteration of the silencing suppression function. Cystein C95 has been shown to be essential for the cell-to-cell movement of protein P1, and C64, F88 essential for the strength of silencing. This contrasts with p19 from the Tomato bushy stunt virus, where a single mutation at G72 is sufficient to abolish the silencing suppression effect on PTGS [47]. These results indicate that silencing suppression might involve several domains in P1, as has been identified for P25 of PVX [35]. Based on the multifunctionality of viral proteins, such mutations could affect other roles involving movement or viral pathogenicity and which could be tested in rice with infectious full-length clones [48]. Mutation C95 was previously introduced in the full-length RYMV cDNA and it has been demonstrated that this full-length was not infectious (Bonneau and Brugidou, unpublished data). Here we demonstrated that this mutation affects cell-to-cell movement of the protein P1, and consequently, silencing suppression activity failed in neighbouring cells. At this point, we cannot conclude if the absence of infectivity was due to absence of viral genomic transport or silencing suppression. However, we demonstrated that P1 movement is necessarily required for the spread of silencing suppression.

\section{Conclusion}

In its natural host we highlighted the functional diversity of RYMV isolates on silencing suppression. The functional diversity at the scale of virion is not correlated to genetic diversity of the P1 protein suppressor. In addition, we demonstrated that this functional diversity is not linked to the virus phylogeny or its pathogenicity. Our overall results suggest that the mechanism of silencing suppression due to the virus is more complex than previously thought. By studying the P1 silencing suppressor alone we demonstrated that the functional diversity of silencing suppression occurs at the P1 protein level and mutagenesis experiments demonstrated that cystein C95 is essential for cell-to-cell movement of P1, and that C64 and F88 are involved in the efficiency of silencing suppression. As both cysteins (C95 and C64) are conserved in the RYMV phylogeny, and as F88 is not, we could assume that this last mutation could be one of the amino acid involved in silencing suppression diversity of $\mathrm{P} 1$. This mutation opens the way to identify other amino acids involved in the functional diversity of silencing suppression.

\section{Abbreviations}

RYMV: rice yellow mottle virus; dsRNA: double strand RNA; miRNA: microRNA; siRNA: small-interfering RNA; PTGS: post-transcriptional gene silencing; ORF: open reading frame; GUS: $\beta$-glucoronidase; uidA: GUS gene; cv: cultivar; O.s: Oryza sativa; TAI: Taipei; BF: Burkina Faso; CI: Ivory Coast; Mg: Madagascar; Ni: Nigeria; Tz: Tanzania; DASElisa: double antibody sandwich-enzyme linked immunosorbent assay; UTR: untranslated region; CaMV: cauliflower mosaic virus; CP: coat protein; GFP: Green fluorescent protein; PVX: potato potexvirus ; EtBr: ethidium bromide; NI: non-inoculated; BI: buffer-inoculated, ND: non-biolistic delivery; BD: biolistic delivery; dpd: day post delivery; del: delivery; dis, distal.

\section{Competing interests}

The authors declare that they have no competing interests.

\section{Authors' contributions}

CS carried out experiments and drafted the manuscript. MB-R participated in the design, cloning, mutagenesis and transitory expression assays; DF participated in the design of experiments in Figs 2, 3, 4 and table 1; CB conceived this project, participated in the study design and coordination and helped to draft the manuscript. All authors read and approved the final manuscript. 


\section{Acknowledgements}

We would like to thank J.P. Brizard, Dr B. Sziurek, Dr P. Agnew for critical reading and corrections of the manuscript. We are grateful to $\mathrm{Dr} E$. Guiderdoni for providing Gus-transgenic rice lines and T. Matthieu for technical assistance. This work was partly supported by a grant from the IRD Expertise and Valuation Department.

\section{References}

I. Aravin AA, Klenov MS, Vagin VV, Rozovskii YM, Gvozdev VA: Role of double-stranded RNA in eukaryotic gene silencing. Mol Biol 2002, 36: $180-188$

2. Hammond SM, Caudy AA, Hannon G): Post-transcriptional gene silencing by double-stranded RNA. Nat Rev Genet 2001, 2:110-119.

3. Meister G, Landthaler M, Dorsett Y, Tuschl T: Sequence-specific inhibition of microRNA- and siRNA-induced RNA silencing. RNA 2004, I 0:544-550.

4. Ding SW, Voinnet O: Antiviral immunity directed by small RNAs. Cell 2007, I30:413-426.

5. Ding SW, Li H, Lu R, Li F, Li WX: RNA silencing: a conserved antiviral immunity of plants and animals. Virus Res 2004, 102:109-II5.

6. Lecellier $\mathrm{CH}$, Voinnet $\mathrm{O}$ : RNA silencing: no mercy for viruses? Immunol Rev 2004, I98:285-303.

7. Wang MB, Metzlaff M: RNA silencing and antiviral defense in plants. Current Opin Plant Biol 2005, 8:2 16-222.

8. Kasschau KD, Carrington JC: A Counterdefensive Strategy of Plant Viruses: Suppression of Posttranscriptional Gene Silencing. Cell 1998, 95:46I-470.

9. Voinnet O, Pinto YM, Baulcombe DC: Suppression of gene silencing: A general strategy used by diverse DNA and RNA viruses of plants. Proc Natl Acad Sci USA 1999, 96:|4|47-|4| 52.

10. Voinnet O, Lederer C, Baulcombe DC: A viral movement protein prevents spread of the gene silencing signal in Nicotiana benthamiana. Cell 2000, 103:157-167.

II. Voinnet O: RNA silencing as a plant immune system against viruses. Trends Genet 2001, I 7:449-459.

12. Anandalakshmi R, Pruss GJ, Ge X, Marathe R, Mallory AC, Smith TH, Vance VB: A viral suppressor of gene silencing in plants. ProC Natl Acad Sci USA 1998, 95: I 3079-13084.

13. Moissiard G, Voinnet O: Viral suppression of RNA silencing in plants. Mol Plant Pathol 2004, 5:71-82.

14. Voinnet $O$ : Induction and suppression of RNA silencing: insights from viral infections. Nat Rev Genet 2005, 6(3):206-220.

15. Abo ME, Sy AA, Alegbjo MD: Rice Yellow Mottle virus (RYMV) in Africa: evolution, distribution, economic significance and sustainable rice production and management strategies. J Sustain Agric 1998, I I:85- I I I.

16. Bakker W: Characterization and ecological aspects of Rice yellow mottle virus in Kenya. In PhD thesis Wageningen; 1974

17. Ngon a Yassi M, Ritzenthaler NC, Brugidou C, Fauquet C, Beachy RN: Nucleotide sequence and genome characterization of rice yellow mottle virus RNA. J Gen Virol 1994, 75:249-257.

18. Qu C, Liljas L, Opalka N, Brugidou C, Yeager M, Beachy RN, Fauquet CM: 3D domain swapping modulates the stability of members of an icosahedral virus group. Structure 2000, 80(10): I095-II03.

19. Fargette D, Pinel A, Abubakar Z, Traore O, Brugidou C, Fatogoma S, Hebrard E, Choisy M, Sere Y, Fauquet C, Konate G: Inferring the evolutionary history of rice yellow mottle virus from genomic, phylogenetic, and phylogeographic studies. J Virol 2004, 78:3252-326I

20. Bonneau C, Brugidou C, Chen L, Beachy RN, Fauquet C: Expression of the Rice Yellow Mottle Virus PI Protein in Vitro and in Vivo and Its Involvement in Virus Spread. Virology 1998, 244:79-86.

21. Himber C, Dunoyer P, Moissiard G, Ritzenthaler C, Voinnet O: Transitivity-dependent and -independent cell-to-cell movement of RNA silencing. EMBO J 2003, 22:4523-4533.

22. Qu F, Morris T]: Suppressors of RNA silencing encoded by plant viruses and their role in viral infections. FEBS Lett 2005 , 579:5958-5964.

23. Fargette D, Pinel A, Halimi H, Brugidou C, Fauquet C, Van Regenmortel $\mathrm{M}$ : Comparison of molecular and immunological typing of isolates of Rice yellow mottle virus. Arch Virol 2002, I 47(3):5863-5896.

24. Traore O, Sorho F, Pinel A, Abubakar Z, Banwo O, Maley J, Hebrard E, Winter S, Sere Y, Konate G, Fargette D: Processes of diversification and dispersion of Rice yellow mottle virus inferred from large-scale and high-resolution phylogeographical studies. Mol Ecol 2005, 14:2097-2II0.

25. Abubakar Z, Ali F, Pinel A, Traore O, N'Guessan P, Notteghem JL, Kimmins F, Konate G, Fargette D: Phylogeography of Rice yellow mottle virus in Africa. J Gen Virol 2003, 84:733-743.

26. Sallaud C, Meynard D, van Boxtel J, Gay C, Bès M, Brizard JP, Larmande $P$, Ortega D, Raynal M, Portefaix M, Ouwerkerk PBF, Rueb S, Delseny $M$, Guiderdoni E: Highly efficient production and characterization of T-DNA plants for rice (Oryza sativa L.) functional genomics. Theor Appl Genet 2003, I 06: I396-|408.

27. Sorho $F$, Pinel $A$, Traoré $O$, Bersoult $A$, Ghesquière $A$, Hébrard $E$, Konaté G, Séré Y, Fargette D: Durability of natural and transgenic resistances in rice to Rice yellow mottle virus. Eur J Plant Pathol 2005, I I 2:349-359.

28. N'Guessan P, Pinel A, Sy A, Ghesquière A, Fargette D: Distribution, pathogenecity and interactions of two strains of rice yellow mottle virus in forested and savannah zones of West Africa. Plant Disease 200I, 85:59-64.

29. Hamilton AJ, Baulcombe DC: A species of small antisense RNA in post-transcriptional gene silencing in plants. Science 1999 , 286:950-95I.

30. Hamilton A, Voinnet O, Chappell L, Baulcombe D: Two classes of short interfering RNA in RNA silencing. EMBO J 2002, 21:467|-4679.

31. Bradford M: A rapid and sensitive method for quantification of microgram quantities of protein utilising the principle of protein-dye binding. Annal Biochem 1976, 72:248-254.

32. N'Guessan $P$, Pinel $A$, Caruana $M$, Frutos $R$, Ghesquière $A$, Fargette $D$ : Evidence of the presence of two serotypes of Rice yellow mottle sobemovirus in Côte d'Ivoire. Eur J Plant Pathol 2000, 106:167-178.

33. Jefferson RA: Assaying chimeric genes in plants: the GUS gene fusion system. Plant Mol Biol Rep 1987, 5:387-405.

34. Jefferson R, Kavanagh T, Bevan M: GUS fusions: beta-glucuronidase as a sensitive and versatile gene fusion marker in higher plants. EMBO J 1987, 6:3901-3907.

35. Bayne EH, Rakitina DV, Morozov SY, Baulcombe DC: Cell-to-cell movement of Potato Potexvirus $X$ is dependent on suppression of RNA silencing. Plant J 2005, 44:47 I-482.

36. Thompson JD, Higgins DG, Gibson TJ: CLUSTAL W: improving the sensitivity of progressive multiple sequence alignment through sequence weighting, positions-specific gap penalties and weight matrix choice. Nucleic Acids Res 1994, 22:4673-4680.

37. van Wezel R, Liu H, Wu Z, Stanley J, Hong Y: Contribution of the zinc finger to zinc and DNA binding by a suppressor of posttranscriptional gene silencing. J Virol 2003, 77:696-700.

38. Roth BM, Pruss GJ, Vance VB: Plant viral suppressors of RNA silencing. Virus Res 2004, 102:97-108.

39. Lu R, Folimonov A, Shintaku M, Li WX, Falk BW, Dawson WO, Ding SW: Three distinct suppressors of RNA silencing encoded by a 20-kb viral RNA genome. Proc Natl Acad Sci USA 2004, I 0 I:| 5742-I5747.

40. Schwartz M, Chen J, Janda M, Sullivan M, den Boon J, Ahlquist P: A positive-strand RNA virus replication complex parallels form and function of retrovirus capsids. Mol Cell 2002, 9:505-514.

4l. van Wezel R, Hong Y: Virus survival of RNA silencing without deploying protein-mediated suppression in Nicotiana benthamiana. FEBS Lett 2004, 562:65-70.

42. Brigneti G, Voinnet O, Li WX, Ji LH, Ding SW, Baulcombe DC: Viral pathogenicity determinants are suppressors of transgene silencing in Nicotiana benthamiana. EMBO J 1998 , I 7:6739-6746.

43. Chen J, Li WX, Xie D, Peng JR, Ding SW: Viral virulence protein suppresses RNA silencing-mediated defense but upregulates the role of MicroRNA in host gene expression. Plant Cell 2004, 16:1302-1313.

44. Kasschau KD, Xie Z, Allen E, Llave C, Chapman EJ, Krizan KA, Carrington JC: PI/HC-Pro, a viral suppressor of RNA silencing, interferes with Arabidopsis development and miRNA function. Dev Cell 2003, 4:205-2I7. 
45. Dunoyer P, Lecellier CH, Parizotto EA, Himber C, Voinnet. O: Probing the microRNA and small interfering RNA pathways with virus-encoded suppressors of RNA silencing. Plant Cell 2004, 16:1235- 1250

46. Opalka N, Brugidou C, Bonneau C, Nicole M, Beachy RN, Yeager M, Fauquet $C$ : Movement of rice yellow mottle virus between xylem cells through pit membranes. Proc Natl Acad Sci USA 1998, 95:3323-3328.

47. Qiu W, Park JW, Scholthof HB: Tombusvirus P I 9-mediated suppression of virus-induced gene silencing is controlled by genetic and dosage features that influence pathogenicity. Mol Plant-Microbe Interact 2002, 15:269-280.

48. Brugidou C, Holt C, Ngon A Yassi M, Zhang S, Beachy RN, Fauquet $C$ : Synthesis of an infectious full-length cDNA clone of rice yellow mottle virus and mutagenesis of the coat protein. Virology 1995, 206: 108-115.

Publish with Bio Med Central and every scientist can read your work free of charge

"BioMed Central will be the most significant development for disseminating the results of biomedical research in our lifetime. "

Sir Paul Nurse, Cancer Research UK

Your research papers will be:

- available free of charge to the entire biomedical community

- peer reviewed and published immediately upon acceptance

- cited in PubMed and archived on PubMed Central

- yours - you keep the copyright

Submit your manuscript here:

http://www.biomedcentral.com/info/publishing_adv.asp
BioMedcentral 